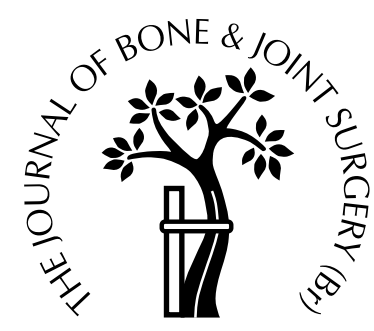

\title{
Acetabular reconstruction with impacted morsellised cancellous bone graft and cement
}

\author{
A 10- TO 15-YEAR FOLLOW-UP OF 60 REVISION \\ ARTHROPLASTIES \\ B. W. Schreurs, T. J. J. H. Slooff, P. Buma, J. W. M. Gardeniers, \\ R. Huiskes \\ From the University Hospital, Nijmegen, The Netherlands
}

$\mathbf{W}^{\mathrm{c}}$ e report a long-term review of 60 acetabular components revised using impacted, morsellised bone allografts and a cemented polyethylene cup. The acetabular defects were cavitary (37) or combined (23). Follow-up was for a mean 11.8 years (10 to 15).

Further revision was needed in five hips, two for septic and three for aseptic loosening. The overall survival rate at 11.8 years was $90 \%$; excluding the septic cases it was $94 \%$.

Acetabular reconstruction with impacted morsellised cancellous grafts and cement gives satisfactory long-term results.

J Bone Joint Surg [Br] 1998;80-B:391-5.

Received 7 November 1997; Accepted 16 December 1997

The main problem in revision hip arthroplasty is the loss of bone stock caused by loosening and the procedures to remove the prosthesis and cement. The replacement of bone stock with bone grafts is an attractive and biological solution.

Based on the experience of Hastings and Parker ${ }^{1}$ and McCollum, Nunley and Harrelson ${ }^{2}$ in hips with protrusio acetabuli, we started to use a modified bone-grafting technique for revision in 1979, using impacted morsellised bone chips and cemented cups. Our results at 2 years ${ }^{3}$ and 5.7 years ${ }^{4}$ were promising, and we now report a longerterm follow-up, including all patients at ten years or more after revision surgery.

B. W. Schreurs, MD, PhD, Orthopaedic Surgeon

T. J. J. H. Slooff, MD, PhD, Professor of Orthopaedics

P. Buma, PhD, Biologist

J. W. M. Gardeniers, MD, PhD, Orthopaedic Surgeon

R. Huiskes, PhD, Professor of Biomechanics

Department of Orthopaedic Surgery, University Hospital, PO Box 9101,

6500 HB Nijmegen, The Netherlands.

Correspondence should be sent to Dr B. W. Schreurs.

(C)1998 British Editorial Society of Bone and Joint Surgery

0301-620X/98/38534\$2.00

VOL. 80-B, No. 3, MAY 1998
Patients and Methods

From January 1979 to March 1986 we performed 62 acetabular reconstructions using impacted morsellised bone grafts in 58 patients with failed hip prostheses. The revisions were performed by a number of surgeons, although one (TJJHS) operated on 50\% of all patients. Two patients were lost to follow-up leaving 56 patients with 60 hips for review. The revision surgery was performed after 43 cemented and six uncemented total hip arthroplasties (THA), eight Wagner double-cup arthroplasties and three failed femoral prostheses. The primary diagnosis had been primary osteoarthritis in 28 hips, secondary osteoarthritis (after childhood diseases) in another 28 and rheumatoid arthritis in four. The indication for revision was aseptic loosening in 56 hips and septic loosening in four. Two patients had had previous revisions, once and twice, respectively.

There were 13 men and 43 women with a mean age at operation of 59.1 years (23 to 82 ). Thirty-five procedures were left-sided and 25 were on the right.

Operative technique. We used the posterolateral approach in all patients with trochanteric osteotomy in only two. After removal of the component, samples from the tissue interface between the component and bone were sent for frozen section and microscopy to detect possible infection. A two-stage procedure was done in the four hips with known septic loosening and in seven with suspected infection, in which more than 50 granulocytes per field were seen on frozen section.

Segmental defects in the medial wall of the acetabulum were closed with a slice of corticocancellous bone. Nine early cases had autografts alone from the iliac crest; later, auto- and allografts were combined in 16 hips and allografts only were used in 35 . In the eight revisions from surface replacement arthroplasty bone grafts were taken from the remains of the resected femoral head. All the allografts were of fresh-frozen femoral heads from the bone bank, with between one and three femoral heads used in each case.

The grafts were morsellised during the operation with a rongeur to provide cancellous chips with a diameter of 0.5 to $1.0 \mathrm{~cm}$. These chips were then impacted with socket trial prostheses, but the trial prosthesis used was at least $2 \mathrm{~mm}$ 
Table I. Details of the first 62 consecutive revisions

\begin{tabular}{llll}
\hline & Acetabular revisions & Patients & \\
\hline Performed from 1979 to 1986 & 62 & 60 & Two lost to follow-up \\
Available & 60 & 58 & Ten died within ten years (no revision) \\
$\quad$ Over ten-year follow-up & 50 & 48 & 2 septic (3y, 6y), 2 aseptic (6y, 9y) \\
Rerevisions by ten-year follow-up & 4 & 4 & 12 years postop \\
Rerevisions after ten years & 1 & 1 & \\
Survival at ten years & All, 92\% & & \\
Survival at a mean of 11.8 years & Excluding infection, 96\% & & \\
& Excluding infection, 94\% & & \\
\hline
\end{tabular}

oversized for the proposed cup diameter to create a cement mantle of sufficient thickness. The original centre of rotation was reconstructed by impaction at the level of the transverse ligament. In 54 hips, the graft was covered with a thin vitallium wire mesh and either a $32 \mathrm{~mm}$ polyethylene Müller or Allopro cup (Sulzer, Winterthür, Switzerland) was cemented using antibiotic-loaded bone cement (Palacos with gentamicin; Merck, Darmstadt, Germany).

Postoperative management included systemic antibiotics for five days, anticoagulation for three months and indomethacin for seven days as prophylaxis against heterotopic ossification. Passive movement was started at 24 hours, walking with partial weight-bearing at six weeks and full weight-bearing after three months.

Clinical data and follow-up. At review in April 1996, 15 patients had died, ten within ten years of the revision. Most of these had been followed up in detail and therefore their data are included. None had had rerevision, and death was unrelated to the hip surgery. Four patients were not seen for late review in our clinic; two were interviewed by telephone and two were reviewed by orthopaedic surgeons in another clinic. The Harris hip score (HHS) was used for clinical evaluation.

Radiological review. Radiological follow-up was complete for 48 patients, incomplete for seven and missing for one. Anteroposterior views of the pelvis were assessed by three authors (TJJHS, BWS and JWMG) who made a consensus opinion. Acetabular defects were assessed from preoperative and first postoperative radiographs and the operation record. The defects were classified as cavitary, segmental or combined using the AAOS classification. ${ }^{5}$ There were 37 cavitary and 23 combined segmental and cavitary defects (10 central and 13 peripheral segmental).

The radiographs at latest review were compared with the first postoperative views and radiolucency was scored in the three zones of DeLee and Charnley, regarding a radiolucent line of more than $2 \mathrm{~mm}$ as positive. Migration was estimated in relation to the interteardrop line. ${ }^{7}$

Definition of failure. Clinical failure was defined as need for revision of the acetabular component for any reason.

Radiological failure was migration of $5 \mathrm{~mm}$ or more in any direction, or progressive radiolucent lines in all three zones. ${ }^{6}$

\section{Results}

Details are given in Table I. Of the 56 patients, 48 were followed for ten years or more; five patients who had died over ten years after the operation are included. The mean follow-up was 11.8 years (10 to 15 ).

Clinical. At final review, no patient had severe pain and the mean HHS was 85 (53 to 100). The HHS had not been recorded before operation, but calculation from available data gave a mean score of 45 .

Rerevisions. Of the five acetabular rerevisions two were for culture-proven septic loosening at three and six years; three were for aseptic loosening at six, nine and 12 years. At ten years, there had been four rerevisions giving an overall survival rate of $92 \%$. If the proven infections are excluded this becomes $96 \%$. The aseptic failure at 12 years reduces the overall survival rate at a mean of 11.8 years (10 to 15 ) to $90 \%$, or excluding infection to $94 \%$.

Other reoperations. Nine hips needed reoperation which did not include the acetabular component. Two showed superficial wound problems; one had periarticular ossification removed and one needed exploration of a trapped sciatic nerve. Two patients had femoral fractures, one traumatic and one pathological due to a metastatic carcinoma. Three patients had femoral rerevisions without exchange of the acetabular component.

Radiological follow-up. Most hips had a stable radiological appearance with uniform radiodensity of graft and host bone (Figs 1 and 2). In one hip, the acetabular component migrated $13 \mathrm{~mm}$ soon after the operation but then remained stable, and was not recorded as a radiological failure. In all three hips rerevised for aseptic loosening and in most with radiological loosening, the radiolucent lines were visible within two years (Fig. 3). Four hips showed radiological loosening by the above criteria at $7,11,13$ and 15 years, respectively. These patients had only mild complaints and three of them had died without rerevision at 7, 12 and 15 years. Other positive radiological signs were a stable radiolucent line in zone I in six hips, a progressive line in zone I in one and a progressive line in zone III in another.

Including both rerevision and radiological loosening the overall survival rate for aseptic loosening was $94 \%$ at ten years and $85 \%$ at 11.8 (10 to 15$)$ years. 


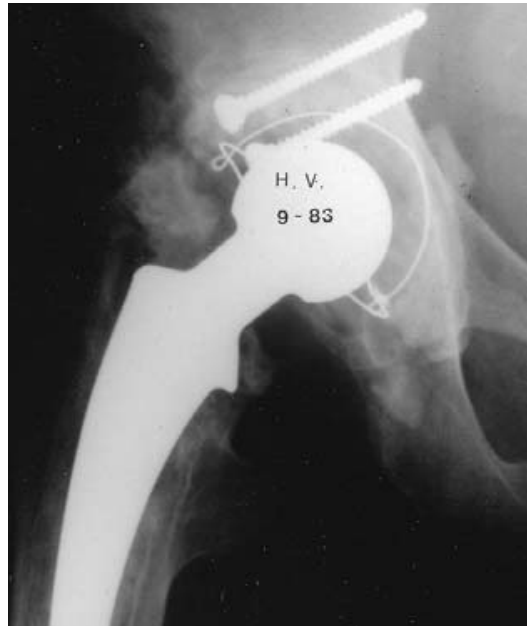

Fig. 1a

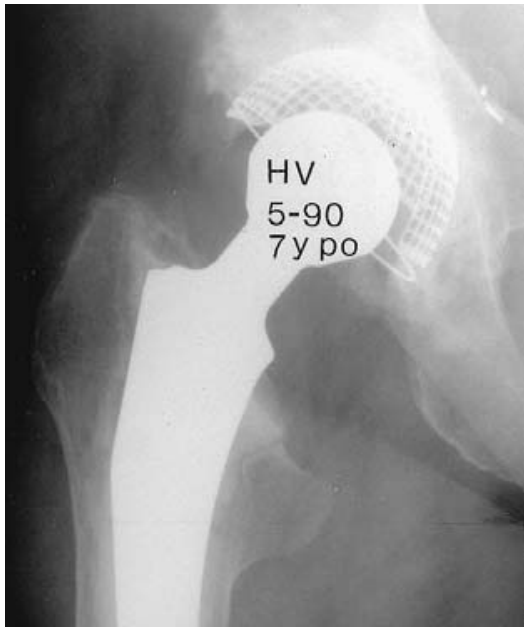

Fig. 1c

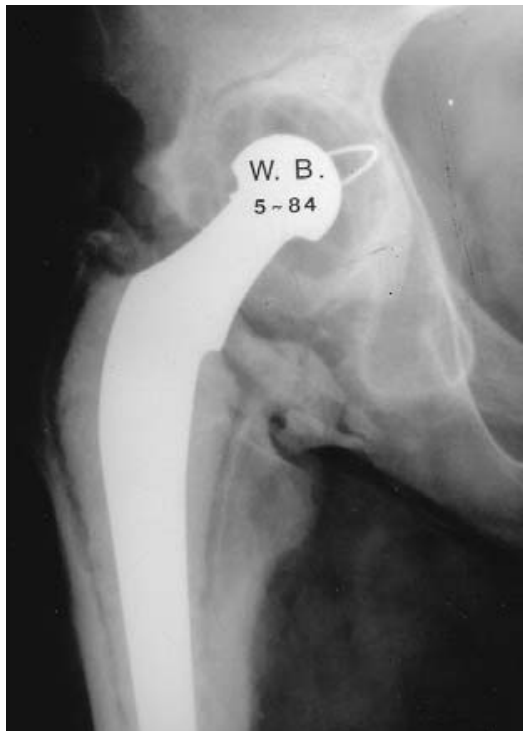

Fig. 2a

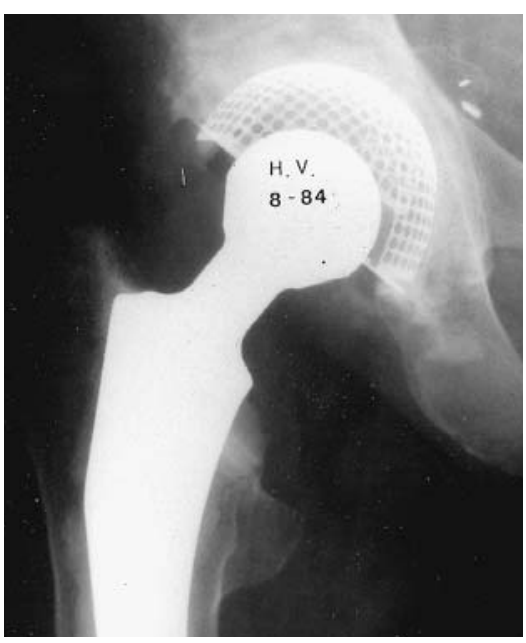

Fig. 1b

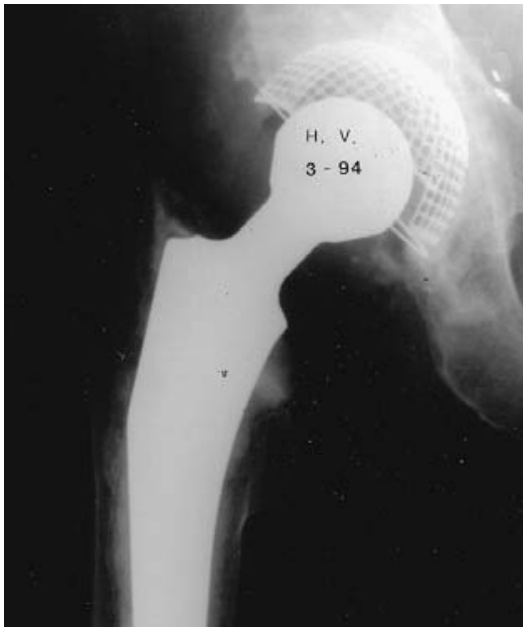

Fig. 1d

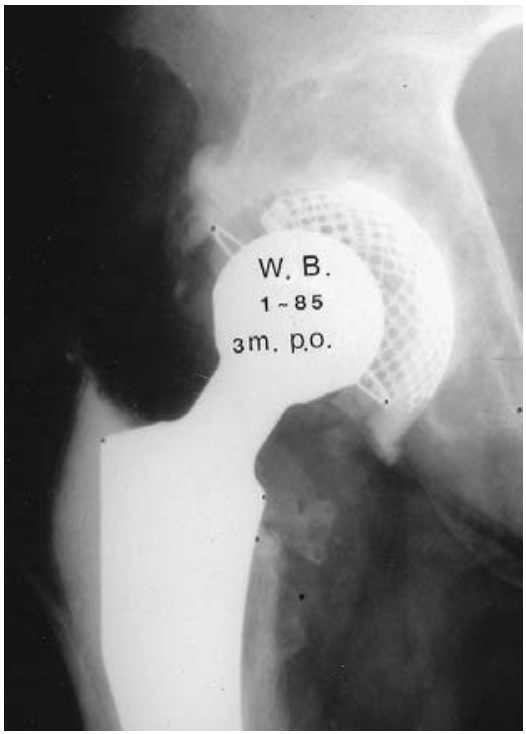

Fig. 2b
Radiographs of a right hip before and after acetabular reconstruction using morsellised graft, wire mesh and cement. Preoperative (a), postoperative (b), six-year (c) and ten-year (d) follow-up views show the incorporation of the reconstruction with no radiolucency.

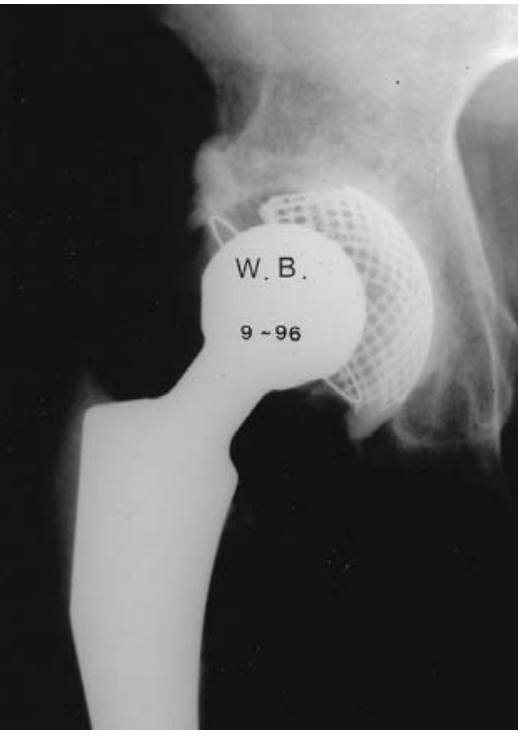

Fig. 2c

Radiographs of a right hip. Preoperative (a), three-month postoperative (b) and 12-year (c) views show trabecular remodelling in the grafted area, with no signs of aseptic loosening. 


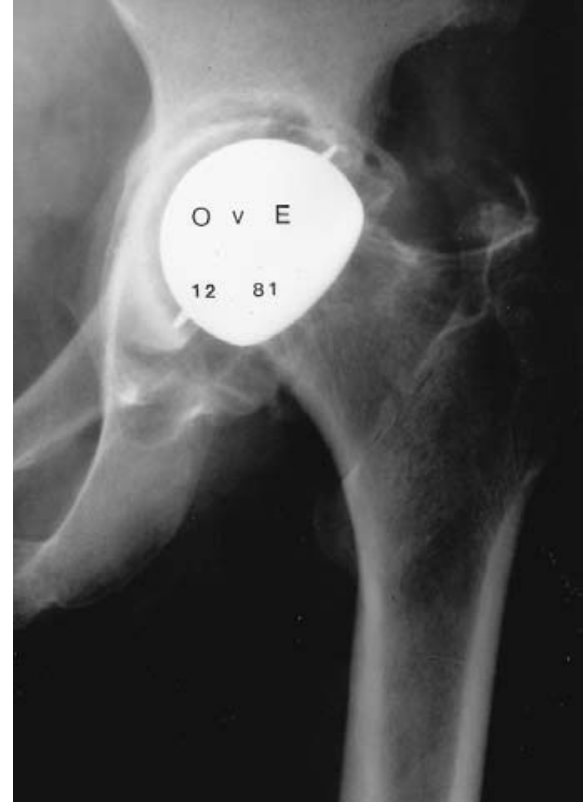

Fig. 3a

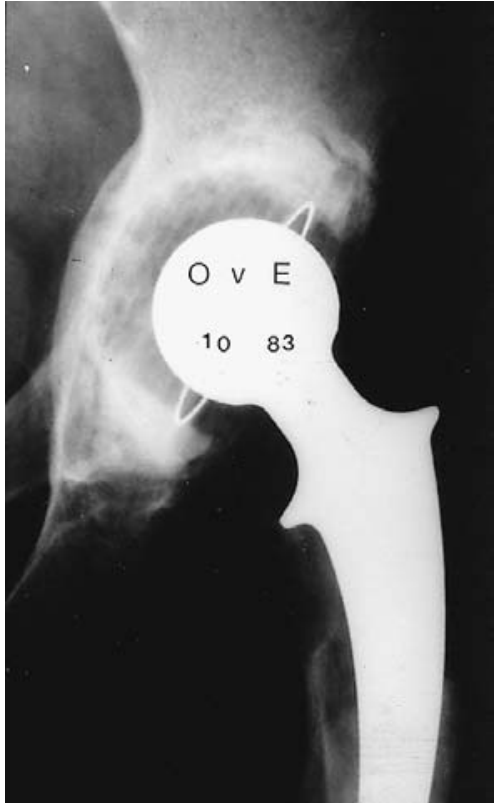

Fig. $3 b$

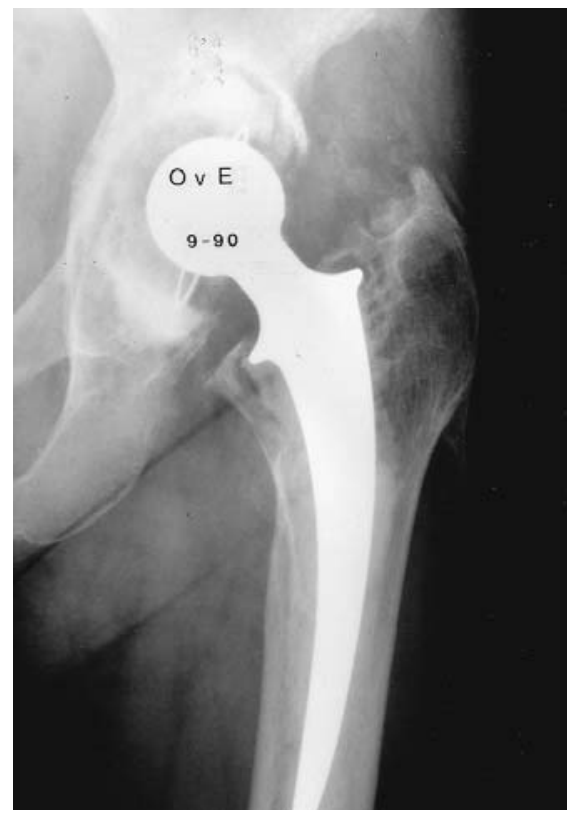

Fig. 3c

Radiographs of a left hip showing failure of a reconstruction. The preoperative view is of a failed resurfacing prosthesis (a). Within nine months after reconstruction a radiolucent line is seen (b), with complete loosening after seven years (c).

\section{Discussion}

There are several options for the reconstruction of acetabular deficiencies, but since 1979 we have used the standard technique of impaction grafting and cement. We consider it important to replace lost bone, restore normal biomechanics and obtain stability. All these can be achieved by impaction grafting and cement. ${ }^{3,4}$

We studied the long-term validity of the technique, by reviewing only patients with a minimum follow-up of ten years. These 60 hips in 56 patients cannot be directly compared with those in our previous report of 88 hips in 80 patients with $95 \%$ survival at a mean 5.7 years. ${ }^{4}$ There has been some deterioration with time.

The reliability of our study was assessed as suggested by Murray, Britton and Bulstrode. ${ }^{8}$ The loss-to-follow-up quotient is 0.4 , and inclusion of the two lost to follow-up as failures gives a 'worst-case' survival of $87 \%$ at 11.8 years for all hips, and $90 \%$ if the infections are excluded.

Conn et $\mathrm{al}^{9}$ has suggested radiological criteria for graft incorporation, but these are difficult to interpret. ${ }^{4,10}$ Incorporation of the grafts can be proved only by histological analysis, but this is difficult in patients. We have reported animal experiments using impacted morsellised allograft in goats on both the acetabular and the femoral sides in combination with THAs. ${ }^{11-13}$ We studied the incorporation process up to 48 weeks, and showed that a remodelling front moved through the impacted allograft from the hostbone junction to the cement-graft interface. We found complete consolidation, revascularisation, and the incorporation of the graft with viable bone marrow by 48 weeks. We have also studied nine human core biopsies from eight patients at between 1 and 72 months after acetabular reconstruction with impaction grafting. ${ }^{14}$ The specimens were taken at reoperation for septic loosening (3), aseptic loosening (2), periarticular ossification (1), a sciatic nerve problem (2) and recurrent subluxation (1). Histological examination of these biopsies suggested that a similar sequence of events took place to that in the animal experiments, with remodelling into a new trabecular bone structure. Heekin et $\mathrm{al}^{10}$ has also shown complete incorporation of morsellised allografts on the acetabular side, and similar results have been found in biopsies of the proximal femur after impaction. ${ }^{15,16}$

By contrast, the incorporation of large structural bone grafts is incomplete, even after a long period. ${ }^{17}$ This has also been observed when autogenous massive femoral head grafts were used for acetabular reconstruction with cemented THAs; ${ }^{18}$ at a mean follow-up of 11.8 years, $20 \%$ had been revised. Shinar and Harris ${ }^{19}$ reported a 16-year follow-up study of relatively young patients (mean age 45.2 years) after both primary and revision THA using both bulk structural autografts and allografts, with a 36\% revision rate for aseptic loosening. Structural acetabular allografts also show a high failure rate after cementless revision arthroplasty, with $18 \%$ acetabular rerevisions within four years. $^{20}$

There have been few long-term studies of revision surgery after failed THA. Marti, Schüller and van Steijn ${ }^{21}$ used superolateral autografts for deficient acetabuli both in primary and revision cemented hip arthroplasties, and at 10.1 years $8 \%$ of the acetabular cups had been revised in primary hip arthroplasties and 14\% in revisions. Silverton et $\mathrm{al}^{22}$ reviewed acetabular revisions without cement after 
THA: at a mean follow-up of 8.4 years, the overall acetabular revision rate was $11 \%$ with an additional $22 \%$ rate for the femoral component.

These long-term results of acetabular impaction grafting with cement are satisfactory, but the technique is very demanding. Impaction must be tight enough to create stability. In all the hips which we report the grafts were morsellised with a rongeur to create chips of a substantial size. The use of bone mills is tempting, but most of them create bone chips of smaller dimensions. There are few data on the influence of the size of chips on stability on the acetabular side. A major concern is the reported use of this technique with bone processed in different ways; the mechanical behaviour of freeze-dried bone may not be comparable with that of the fresh-frozen grafts which we used. Finally, the role of postoperative management is not clear. All the patients whom we report had a strict protocol of bedrest for six weeks, but because of the relatively high morbidity and cost of this, we now mobilise most of our patients on crutches at three weeks. The period of immob-

\section{References}

1. Hastings DE, Parker SM. Protrusio acetabuli in rheumatoid arthritis. Clin Orthop 1975;108:76-84.

2. McCollum DE, Nunley JA, Harrelson JM. Bone-grafting in total hip replacement for acetabular protrusion. J Bone Joint Surg [Am] 1980; 62-A:1065-73.

3. Slooff TJJH, Huiskes R, van Horn J, Lemmens AJ. Bone grafting in total hip replacement for acetabular protrusion. Acta Orthop Scand 1984;55:593-6.

4. Slooff TJ, Schimmel JW, Buma P. Cemented fixation with bone grafts. Orthop Clin North Am 1993;24:667-77.

5. D'Antonio JA, Capello WN, Borden LS, et al. Classification and management of acetabular abnormalities in total hip arthroplasty. Clin Orthop 1989;243:126-37.

6. DeLee JG, Charnley J. Radiological demarcation of cemented sockets in total hip replacement. Clin Orthop 1976;121:20-32.

7. Garbuz D, Morsi E, Mohamed N, Gross AE. Classification and reconstruction in revision acetabular arthroplasty with bone stock deficiency. Clin Orthop 1996;324:98-107.

8. Murray DW, Britton AR, Bulstrode CJK. Loss to follow-up matters. J Bone Joint Surg [Br] 1997;79-B:254-7.

9. Conn RA, Peterson LFA, Stauffer RN, Ilstrup D. Management of acetabular deficiency: long-term results of bone grafting the acetabulum in total hip arthroplasty. Orthop Trans 1985;9:451-2.

10. Heekin RD, Engh CA, Vinh T. Morselized allograft in acetabular reconstruction: a postmortem retrieval analysis. Clin Orthop 1995; 319:184-90.

11. Schreurs BW, Buma P, Huiskes R, Slagter JL, Slooff TJ. Morsellized allografts for fixation of the hip prosthesis femoral component: a mechanical and histological study in the goat. Acta Orthop Scand 1994;65:267-75.

12. Schreurs BW, Huiskes R, Buma P, Slooff TJ. Biomechanical and histological evaluation of a hydroxyapatite-coated titanium femoral stem fixed with an intramedullary morsellized bone grafting technique: an animal experiment on goats. Biomaterials 1996;17: 1177-86. ilisation must be adjusted in relation to the original extent of destruction.

Conclusions. Large defects at revision surgery must be treated, and we believe that the best solution is biological, using bone graft to reconstruct the skeleton. Our review has evaluated one specific technique of replacing the bone defect with impacted cancellous morsellised bone. This then allows conventional implants, as used in primary procedures, to be placed in an anatomical position with a thin, even layer of cement. We do not replace loose, defective prostheses with larger cups or greater amounts of cement, and we have excellent clinical results at over ten years. Both radiological incorporation and histological evidence tend to confirm that bone stock is restored to create a situation which is as close to nature as possible.

We thank Mrs M. Welten for her participation in the radiological study, and Mr T. Winkelhorst and J. van Unen for the collection of patients' data. We also thank Mr J. Older (Midhurst, UK) for critically reviewing the manuscript.

The Department of Orthopaedics receives financial support for fundamental research.

13. Schimmel JW, Buma P, Huiskes R, Slooff TJJH. Acetabular reconstruction with impacted morsellized cancellous allografts in cemented hip arthroplasty: a histological and biomechanical study on the goat. J Arthroplasty 1997:in press.

14. Buma P, Lamerigts N, Schreurs BW, et al. Impacted graft incorporation after cemented acetabular revision: histological evaluation in 8 patients. Acta Orthop Scand 1996;67:536-40.

15. Ling RSM, Timperley AJ, Linder L. Histology of cancellous impaction grafting in the femur: a case report. J Bone Joint Surg [Br] 1993;75-B:693-6.

16. Nelissen RG, Bauer TW, Weidenhielm LR, LeGolvan DP, Mikhail WE. Revision hip arthroplasty with the use of cement and impaction grafting: histological analysis of four cases. J Bone Joint Surg [Am] 1995;77-A:412-22.

17. Mankin HJ, Gebhardt MC, Jennings LC, Springfield DS, Tomford WW. Long-term results of allograft replacement in the management of bone tumours. Clin Orthop 1996;324:86-97.

18. Mulroy RD, Harris WH. Failure of acetabular autogenous grafts in total hip arthroplasty: increasing incidence. J Bone Joint Surg [Am] 1990;72-A:1536-40.

19. Shinar AA, Harris WH. Bulk structural autogenous grafts and allografts for reconstruction of the acetabulum in total hip arthroplasty. J Bone Joint Surg [Am] 1997;79-A:159-68.

20. Hooten JP Jr, Engh CA Jr, Engh CA. Failure of structural acetabular allografts in cementless revision hip arthroplasty. J Bone Joint Surg [Br] 1994;76-B:419-22.

21. Marti RK, Schüller HM, van Steijn MJA. Superolateral bone grafting for acetabular deficiency in primary THR and revision. J Bone Joint Surg [Br] 1994;76-B:728-34.

22. Silverton CD, Rosenberg AG, Sheinkop MB, Kull LR, Galante JO. Revision of the acetabular component without cement after total hip arthroplasty: a follow-up note regarding results at seven to eleven years. J Bone Joint Surg [Am] 1996;78-A:1366-70. 